\title{
\begin{tabular}{l|l} 
pcori)? & PATIENT-CENTERED OUTCOMES RESEARCH INSTITUTE \\
RESEARCH SUMMARY
\end{tabular}
}

\section{Developing Methods to Account for Bias from Unmeasured Sources When Analyzing Time Until a Health Event}

Principal investigator

Organization

Alistair James O'Malley, BSc (Hons), MS, PhD

Dartmouth College

\section{What was the project about?}

Researchers often use data from patients' health records to compare treatments. But many things-not just treatments-affect patients' health. To figure out whether changes in patients' health result from treatment or something else, researchers can use statistical methods called instrumental variables, or IVs. IV methods account for factors that affect health but aren't in patients' health records, such as eating habits. Existing IV methods work well when looking at health outcomes that are measured using certain types of scales, such as blood pressure. But existing methods don't work as well to measure the time until a health event occurs, particularly when an event, like death, has not occurred for many patients in the study.

In this study, the research team created and tested a new IV method to more accurately estimate how a treatment relates to the time until a health event.

\section{What did the research team do?}

The research team created 2SRI-F, a new IV method. The team then created a test data set to mimic patient health records. The test data set included information on patients' health and treatments. Using the test data, the team compared findings using the new IV method with findings from existing methods.

The research team also tested the new method in three studies using data from patients with blood vessel diseases who had health records in the Vascular Quality Initiative, or VQI. Studies 1 and 2 looked at the effect of treatment type on time to death. Study 3 estimated the effect of treatment on time until having an amputation or until a patient had to start treatment again. In all three studies, the research team compared findings from the $2 \mathrm{SRI}-\mathrm{F}$ method to those from existing methods.

Patients, physicians, and the VQI director helped the research team design the study.

\section{What were the results?}

Compared with existing methods, the 2SRI-F method had more accurate results. The results from the $2 \mathrm{SRI}-\mathrm{F}$ method were more similar to results found in randomized trials. Researchers consider these trials the best way to compare how well treatments work.

\section{What were the limits of the project?} Current computer programs cannot make estimates for the new methods that are as precise as researchers would like. These programs are not designed to run the $2 \mathrm{SRI}-\mathrm{F}$ method.

Future research could improve computer programs to analyze data using the 2SRI-F method.

\section{How can people use the results?}

Researchers can use the results when designing studies using data from patient health records.

To learn more about this project, visit www.pcori.org/OMalley290. 